\title{
A Multilevel Input-Oriented English Teaching Model considering Diversified Training Objectives
}

\author{
Q. I. Yan-fei \\ School of Foreign Languages, Hanjiang Normal University, Shiyan 442000, China \\ Correspondence should be addressed to Q. I. Yan-fei; 20202149@stu.nun.edu.cn
}

Received 23 December 2021; Revised 15 January 2022; Accepted 31 January 2022; Published 23 February 2022

Academic Editor: Zhiguo Qu

Copyright @ 2022 Q. I. Yan-fei. This is an open access article distributed under the Creative Commons Attribution License, which permits unrestricted use, distribution, and reproduction in any medium, provided the original work is properly cited.

\begin{abstract}
At present, the existing English teaching model is not constructed according to the LASeR standard, resulting in the low I/O performance of the English teaching model and the decline of students' learning efficiency. A multilevel input English teaching model considering diversified training objectives is proposed. Split the semantic features of multilevel input English teaching model information, calculate the support value of data items in the English teaching model resource database, and delete the complex and large amount of resource information. And with the probability vector diagram allocation method to match the autocorrelation characteristics of teaching resources, based on the relevant feature extraction results, complete the efficient mining of multilevel input-oriented English teaching model resources and realize the construction of multilevel input-oriented English teaching model considering diversified training objectives. The experimental results show that the designed model has high I/O performance and effectively improves students' learning efficiency.
\end{abstract}

\section{Introduction}

With the economic and social development and the gradual increase of foreign exchange activities, the discipline status of English majors has been greatly improved, and the number of English majors in China has increased sharply, almost forming a situation that as long as colleges and universities can "create conditions" to set up English majors [1,2]. However, the rapid development of English majors not only promotes the prosperity of foreign language disciplines but also causes people's general anxiety and confusion $[3,4]$. In the controversy over the reform of the foreign language college entrance examination in 2013, some provinces and cities in China put forward reform plans such as withdrawing English from the unified college entrance examination and reducing the score of the college entrance examination, which triggered a new round of discussion on English teaching in the field of College English Education [5]. In order to meet the needs of the talent market, colleges and universities have considered diversified training objectives and successively carried out the exploration of compound talent training, that is, from single subject English major to multisubject applied discipline. At the same time, English majors are kidnapped by marketization, low-end, and instrumentalization to a great extent, and their sustainable development is facing increasingly severe challenges.

Relevant scholars have done a lot of research. Reference [6] proposes to evaluate the English teaching plan from the perspective of peace education and the 12th grade English teaching plan (ELTP) in Turkey. It is designed as a qualitative study. The new 12th grade ELTP was used to collect data. The data were analyzed by literature analysis. The survey results show that the new ELTP is combined with peace education through its nine units' themes, target language functions, and learning objectives. The results also show that the new ELTP can teach students personal peace, peace with human families, and peace with nature. The research results are discussed according to the literature. Reference [7] proposes learner centered English teaching and the adaptability of learner centered education and examines how university teachers implement learner centered education in second language teaching since the learner centered education reform was launched ten years ago. In this process, a questionnaire was distributed to a random sample of 128 
teachers. The collected data were analyzed by descriptive and inferential statistical analysis using the social science statistical software package SPSS16.0. At the same time, the interview was analyzed qualitatively. The quantitative analysis of data provides a snapshot of teachers' attitude towards learner centered education and the degree of education they implement in the curriculum. More importantly, the analysis of qualitative interview results outlines a "situational" framework, which takes into account the conceptual nature of the global premise of learner centered education and links it with teachers' cognition and practice in specific situations. These findings provide impetus to meet the second language learning needs of college students. Based on the above research, a multilevel input-oriented English teaching model considering diversified training objectives is proposed. Firstly, the model divides the information semantic features of multilevel input-oriented English teaching model, calculates the data item support value in the English teaching model resource database, and deletes the complex and computationally intensive resource information. Then, the probability vector diagram allocation method is used to match the autocorrelation characteristics of teaching resources. Based on the correlation feature extraction results, considering the diversified training target factors, the purpose of building a multilevel input-oriented English teaching model is realized. The results show that the designed model has high I/O performance and can effectively improve students' learning efficiency.

\section{Information Preprocessing of the Multilevel Input-Oriented English Teaching Model}

2.1. Information Semantic Feature Segmentation of the Multilevel Input English Teaching Model. The multilevel input English teaching model repository is defined as $d_{n}$, which is segmented according to the keywords of English words and resource types $[8,9]$. The self characteristic | $d_{n-\max }-d_{n-\min } \mid(1 / k)$ of resource types is divided into $k$ data subsets $A_{k}$ by the adaptive equilibrium segmentation method and $A_{k}$ meets the following conditions:

$$
A=A_{1} \cup A_{2} \cup \cdots \cup A_{k}
$$

Formula (1) refers to the semantic features and search set of the multilevel input English teaching model. Since the use environment and scope of the multilevel inputoriented English teaching model are different [10], build a network model that meets its conditions for each environment and consider diversified training objectives, so that the state distribution of the multilevel input-oriented English teaching model can meet the following conditions:

$$
A_{i} \cap A_{j}=\Omega_{i j}
$$

In the formula, $\Omega_{i j}$, A represents the state distribution set, $i, j=1,2, \cdots, k$ and . After completing the above operations, a multilevel input-oriented English teaching model is built according to the decision tree, and the feature mining access control model is established.

Firstly, an empty node root is selected as the root node according to the semantic characteristics, the branch structure model is constructed at the corresponding parent node, and the rule data set is used to match the two nodes in the resource database $[11,12]$. Considering the diversified training objectives, and then taking the node as the search node for calculation, the adaptive probability distribution value of semantic feature segmentation is 0.56 . Based on 0.56 , the decision tree model is constructed to obtain the semantic feature segmentation results of the multilevel input English teaching model as shown in formula (3):

$$
H(x)=\sum_{k=1}^{K} p_{k} \ln \frac{1}{p_{k}}=-\sum_{k=1}^{K} p_{k} \ln p_{k} .
$$

In the formula, $H(x)$ represents the semantic feature segmentation function, and the output result of the function is the segmentation result. $x$ represents the amount of the multilevel input English teaching model $[13,14], K$ represents the number of semantic segmentation in the multilevel input English teaching model [15], and $p_{k}$ represents the posterior probability distribution value after semantic feature segmentation in the multilevel input English teaching model, which is a finite value. According to the calculation results of equation (3), the semantic feature segmentation of the multilevel input English teaching model pays more attention to small goals or divides the large goals into multiple parts. It is of great significance to obtain fine segmentation, which can realize the semantic feature segmentation of the information of the multilevel input English teaching model.

2.2. Support Calculation of Data Items in the Multilevel Input English Teaching Model. $\varphi_{D}(I)$ is used to represent the support function of the itemset $I$ in the multilevel input English teaching model base $D$, min sup is the minimum support function value, and $|T|$ is the size of the transaction $T$ in the resource base, that is, the number of resources contained in $T$. The length of itemset $d$ is represented by $|d|$.

The size of the multilevel input English teaching model base $D$ is fixed, and the frequency of item set $I$ has nothing to do with the resources smaller than $|I|$. In resource pool $D$, there is a frequent $s$ itemset $I_{s}$, that is,

$$
\varphi_{D}\left(I_{s}\right) \geq \min \sup
$$

If the resource pool $D^{\prime}=\{d|d \in D \wedge| d \mid \geq l>s\}$, assuming $\varphi_{D^{\prime}}\left(I_{s}\right)<\min$ sup, there is a frequent $l$ itemset $I_{l}$ in the resource pool $D$ and $I_{s} \not \subset I_{l}$.

Assuming $I_{s} \subset I_{l}$, if $d \in D$ and $|d|<l, \varphi_{D}\left(I_{l}\right)$ does not affect whether $d$ itemsets exist in the resource pool; so, $\varphi_{D}($ $\left.I_{l}\right)=\varphi_{D^{\prime}}\left(I_{l}\right)$, and because $I_{l}$ is a frequent itemset, $\varphi_{D^{\prime}}\left(I_{l}\right) \geq$ min sup. Since the subset of frequent itemset is also a frequent itemset, $\varphi_{D^{\prime}}\left(I_{s}\right) \geq \min$ sup, if it contradicts the preconditions, the proof is completed.

Based on the above reasoning process, the support degrees of frequent $s$ itemsets item ${ }_{i}$ and item ${ }_{j}$ are calculated, 
respectively, and the binary $\left(i_{s}, i_{s+1}, \cdots, i_{q}\right)$ and $\left(j_{s}, j_{s+1}, \cdots\right.$, $\left.j_{q}\right)$ are obtained; that is, $\sum_{p=s+1}^{q} \min \left(i_{p}, j_{p}\right) \geq \min \sup$ and item $_{i} \cap$ item $_{j} \mid=s-1$ are one of the essential conditions to form the resource database.

Therefore, when $\sum_{p=s+1}^{q} \min \left(i_{p}, j_{p}\right)<\min$ sup, item $i$ and item $_{j}$ do not belong to the necessary conditions for constituting the resource pool.

After the necessary conditions are verified, the verification calculation is ended.

It can be seen from the assumptions that considering the diversified training objectives, when the calculation length is greater than the support value of itemset $s$, it is not necessary to continue to solve the itemset with length greater than $s$. Therefore, through the support calculation, the information with scale greater than $s$ in the resource library can be deleted while determining the composition of itemset $s$; that is, the information with more complex or large amount of calculation can be deleted and facilitate the efficient mining of multilevel input-oriented English teaching model in the later stage $[16,17]$.

Assuming $L_{s}$ is the set of item set $s$ and $L C_{s} \subseteq L_{s}$ is the seed item set, the potential item set is obtained by calculating $L C_{s}$, and then the size of $L C_{s}$ directly affects the overall computational efficiency of the algorithm.

In the process of calculating the support of the data items of the multilevel input English teaching model [18], due to the piecewise calculation, given an upper bound 1 umit of the length of a frequent $u$ item set through assumptions, $\sum_{u=l}^{q} f_{u}>$ min sup can be obtained, and $l$ is an upper bound at this time. The relatively minimum upper bound can also be found by the above method. The upper bound found here does not represent the final upper bound of the algorithm. Through assumptions, the constraints of frequent itemsets are obtained, which also ensures the mining accuracy of multilevel input English teaching model to a certain extent, obtains different information, improves the support of data items of the multilevel input English teaching model, the ability of different scale objectives, and achieves better semantic segmentation effect and better support calculation results.

\subsection{Exploration of Multilevel Input-Oriented English} Teaching Curriculum Resources. Take the distributed file system as the storage module and map reduce as the implementation platform of cloud computing and mine the multilevel input English teaching model on this platform $[19,20]$. The architecture of resource mining algorithm of the multilevel input English teaching model considering diversified training objectives is shown in Figure 1.

As can be seen from Figure 1, the architecture of the multilevel input English teaching model mining algorithm consists of the multilevel input English teaching model resource display module, multilevel input English teaching model resource data flow module, and multilevel input English teaching model resource mining system module. The multilevel input oriented English teaching model is composed of resource processing and loading module and cloud computing processing platform module. The multilevel input English teaching model mining algorithm structure has the advantage of fast mining speed.

2.3.1. Mining Autocorrelation Features of the Multilevel Input-Oriented English Teaching Model. Through the above semantic feature segmentation and support calculation of the multilevel input English teaching model and then using the adaptive cascade retrieval control to realize the efficient mining of the multilevel input English teaching model [21, 22], $c$ is defined as a subset of words existing in the resource library, and there are $G$ constraint vectors in the resource library. Directed indicator diagrams $G(A)$ and $G(B)$ are established to represent the word distribution characteristics of the multilevel input English teaching model base [23, 24], $\langle x, y\rangle$ is a pair of nodes in $A$ and $B$, and the fitting model of teaching resource flow is

$$
M_{v}=w_{1} \sum_{i=1}^{m \times n}\left(H_{i}-S_{i}\right)+w_{2} \sum_{i=1}^{m \times n}\left(S_{i}-V_{i}\right)+w_{3} \sum_{i=1}^{m \times n}\left(V_{i}-H_{i}\right) .
$$

Using the idea of cloud computing and considering diversified training objectives, it is determined that the average load balance value $M_{h}$ of the optimal allocation, and scheduling of the multilevel investment English teaching model is

$$
M_{h}=\frac{\sum_{j=1}^{N} M_{v} \times q_{j}}{U(u) / N}
$$

In the formula, $q_{j}$ represents the number of requests for access to the multilevel input English teaching model [25], $U(u)$ indicates the actual viewing amount of English resources, and $N$ represents the actual number of visits to the multilevel input English teaching model base [26]

By constructing the priority list of the multilevel inputoriented English teaching model through the support function value calculated above, the autocorrelation characteristics of English teaching can be obtained as follows:

$$
x(t)=\sum_{i=1}^{n} c_{i} r_{n}
$$

In the formula, $c_{i}$ represents the component value of autocorrelation eigenfunction of the multilevel input English teaching model, and $r_{n}$ represents the higher-order cumulative coefficient of the multilevel input English teaching model distributed in the platform [27]. According to the calculation results of equation (7), the efficient mining of autocorrelation features of the multilevel input-oriented English teaching model can be realized.

2.3.2. Multilevel Input-Oriented English Teaching Model Mining Based on Adaptive Cascade Retrieval Control. Using the idea of probability vector diagram of the multilevel input English teaching model (as shown in Figure 2), considering 


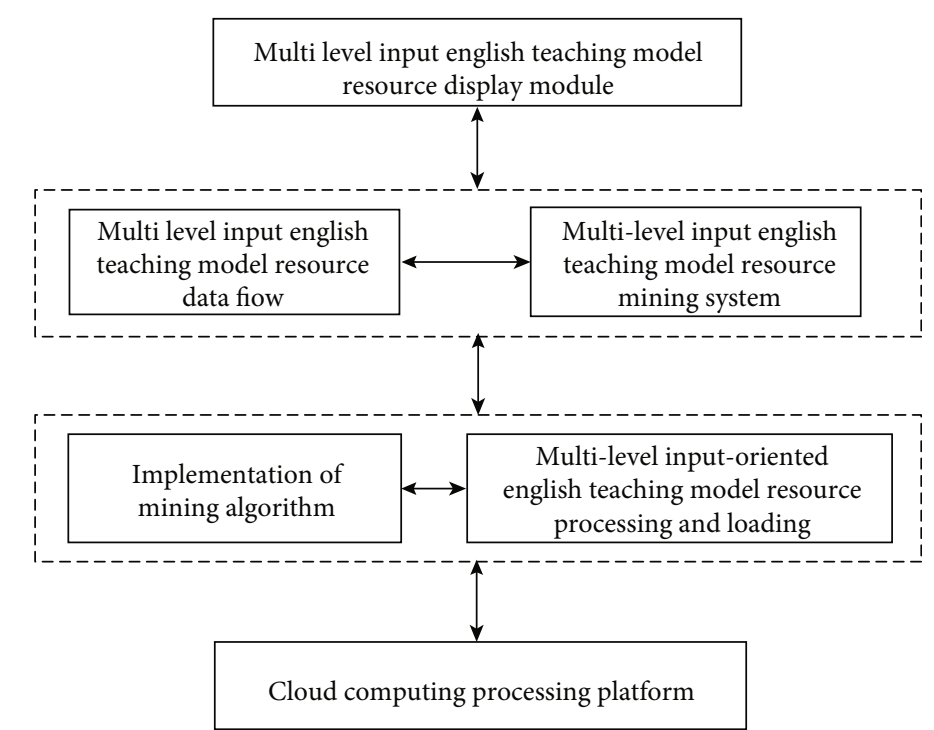

FIGURE 1: Mining algorithm of the multilevel input English teaching model.

\begin{tabular}{|c|c|c|c|c|c|}
\hline$\alpha_{1}$ & 0.9 & 0.9 & 0.3 & 0.6 & 0 \\
\hline$\alpha_{2}$ & 0.3 & 0.6 & 0.7 & 0 & 0.9 \\
\hline$\alpha_{3}$ & 0.7 & 0.1 & 0.1 & 0 & 0.9 \\
\hline$\alpha_{4}$ & 0.7 & 0 & 0.7 & 0 & 0.3 \\
\hline
\end{tabular}

FIgURE 2: Mining probability vector diagram of the multilevel input English teaching model.

diversified training objectives, search all distribution nodes in the multilevel input English teaching model [28] and obtain the effective function $E(i, j)$ of adaptive equilibrium control as follows:

$$
E(i, j)= \begin{cases}\frac{e_{i j}-e(i, j)}{e_{\max }-e(i, j)}, & e(i, j)<e_{i j} \\ \frac{e_{i j}-e(i, j)}{e(i, j)-e_{\min }}, & e(i, j) \geq e_{i j} .\end{cases}
$$

In the formula, $e(i, j)$ represents the similarity function value of the teaching resource distribution node, $e_{i j}$ represents the effective threshold of the teaching resource distribution node, and $e_{\max }$ and $e_{\min }$ represent the maximum and minimum threshold, respectively.

According to Figure 2, set the constraint weights of the multilevel input English teaching model base as $\alpha_{1}, \alpha_{2}, \alpha_{3}$, and $\alpha_{4}$, and the four weights meet the parameter constraint condition $\alpha_{1}+\alpha_{2}+\alpha_{3}+\alpha_{4}=1$. Considering the diversified training objectives, the time function of the information flow node set $t_{i}$ of the multilevel input English teaching model is expressed by equation (9):

$$
T(i, j)= \begin{cases}\frac{t_{i j}-t(i, j)}{t_{i j}}, & t(i, j)<t_{i j}, \\ 0, & t(i, j) \geq t_{i j} .\end{cases}
$$

In the formula, $t_{i j}$ represents the optimal time threshold for scheduling multi-level input English teaching model base, and $t(i, j)$ represents the similarity function value of the same type of resources in different time periods. Use equation (10) to iteratively calculate the adaptive cascade list of the multilevel input English teaching model:

$$
x_{i}(t)=x_{i}(t-1)+s\left(\frac{x_{j}(t-1)-x_{i}(t-1)}{\left\|x_{j}(t-1)-x_{i}(t-1)\right\|}\right) \text {. }
$$

Assuming that the center distance between the cluster $M_{i}$ and $M_{j}$ of the storage nodes in the two multilevel input English teaching model bases is $\operatorname{Clustdist}\left(M_{i}, M_{j}\right)$, when $i$ $\neq j, 1 \leq i \leq q$, and $1 \leq j \leq q$, considering the diversified train- 
ing objectives, the mining query link fitness function of the multilevel input English teaching model should meet the conditions of equation (11):

$$
p\left(Q_{s}\right)=\frac{1}{\sqrt{2 \pi} \sigma_{s}} \exp \left[-\left(Q_{s}-\left\langle Q_{s}\right\rangle\right)^{2} /\left(2 \sigma_{s}^{2}\right)\right] .
$$

In the formula, $Q_{s}$ represents the statistical frequency parameter generated in the mining process of the multilevel input-oriented English teaching model. Through this method, the candidate data item set and frequent item set of the multilevel input English teaching model can be analyzed, respectively, and the mining efficiency and accuracy of the multilevel input English teaching model in massive data can be greatly improved.

\section{Realize the Multilevel Investment English Teaching Model}

The multilevel input English teaching model is mainly constructed according to the $\mathrm{C} / \mathrm{S}$ architecture; that is, two windows of server and client are set in the system, and the English teaching model is divided into two areas: scene distribution and reuse transmission $[29,30]$, in which the scene distribution is composed of spatial distribution and temporal distribution, so as to improve the scalability and universality of the model. Considering the diversified training objectives, the scene distribution is updated through SVG using LASeR instruction, and the multiplexed video data is saved and put into use. The client mainly receives the server data and demultiplexes its multiplexed stream and then transmits the video data to the display for playback. Its flowchart is shown in Figure 3.

As can be seen from Figure 3, the overall framework of the multilevel input English teaching model is mainly composed of two parts: server and display. The multilevel input English teaching model is a way to integrate different levels of features. Using shallow features to repair the spatial details of deep feature map can further enhance the effect and robustness of English teaching.

3.1. Server Design. Because the teaching video under the LASeR standard has the characteristics of streaming video, a dual function server including portal website and streaming video server needs to be established for the teaching server. Because the multilevel input English teaching model involves a wide range of contents [31], and considering the diversified training objectives, the relevance between different contents is strong. Therefore, it is necessary to reorganize the internal data of the server. Since streaming video is an important part of the data, and the data must be input and reused. In order to improve the video quality to the greatest extent, the server needs to build a dynamic and exquisite scene distribution, so as to ensure the flexibility of the multi-level input English teaching model.

LASeR can automatically adjust the scene distribution according to the resolution of the device based on the SVG vector characteristics, so as to ensure the best video quality [32]. Svg can also use the position, size, and other character-

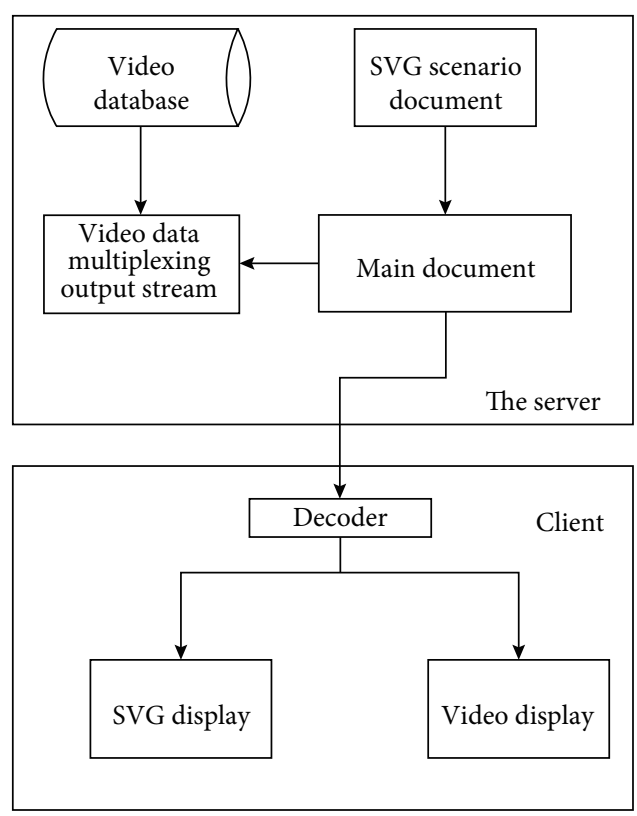

FIgURE 3: Overall framework of the multilevel input English teaching model.

istics of the basic video graphics to convert them into vector images, map them to the canvas for spatial distribution, set the video projection, stop time and video-related time data for time distribution, so as to generate SVG scene tree, and add LASeR instructions to the LASeR packet to obtain scene files. The file compression coding function is established based on the syntax characteristics of the scene file to ensure that the video is compressed to the greatest extent without affecting the video effect LASeR.

In order to improve the investment efficiency of the multilevel input-oriented English teaching model, the scene can be arranged through the LASeR instruction, and the SVG scene tree can be analyzed by DOM to ensure that the LASeR instruction can operate the video nodes smoothly and achieve efficient scene distribution [33]. Because streaming transmission uses the audio and video server to transmit sound, image, and other data to users in real time, users can download while watching. The overall process can be realized in a few seconds, which can greatly improve the teaching efficiency and reduce the cache capacity [34].

In the process of video transmission, a fixed bit rate is usually set to avoid the burst of transmission, but English teaching video is one of time-based media; so, it has very strict real-time performance. Therefore, the teaching server usually sends it in real time according to the teaching time, and CBR media is selected to transmit information based on the above requirements. The data transmission bit rate when the server is put into operation is in line with the real-time performance of the media.

Through the corresponding linear relationship of data, an input device with and only one corresponding transmission timestamp for bit video data transmitted in packet mode can be designed. Generally, the first timestamp in the transmission process is set as the timestamp of the whole data packet. The data packet size of video in the 


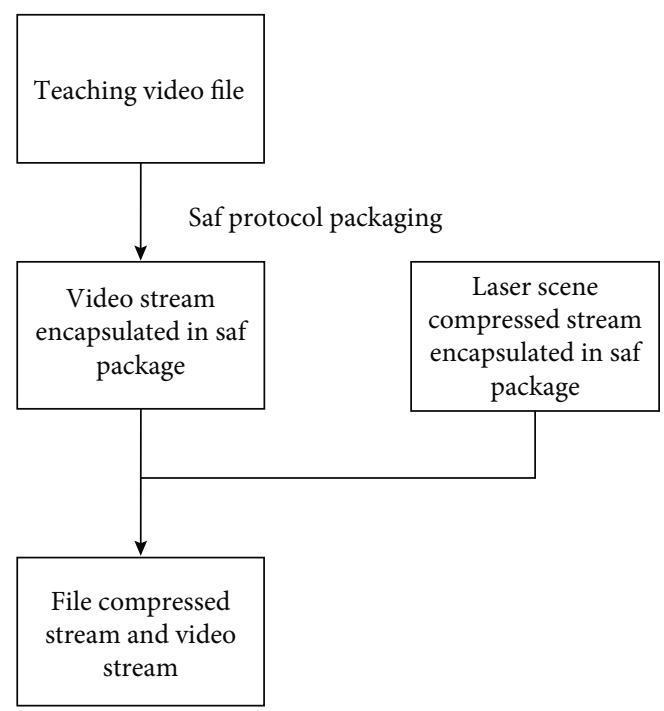

FIGURE 4: Structure diagram of video packaging multiplexing.

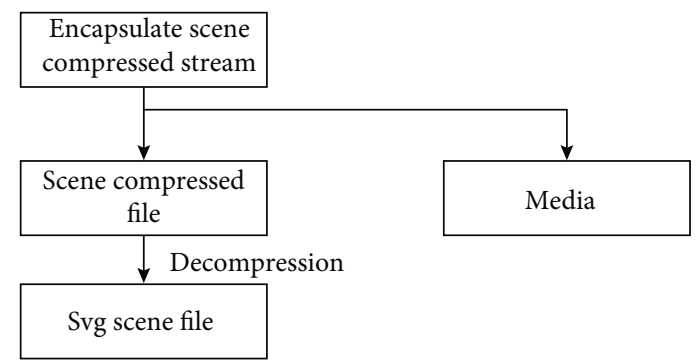

FIGURE 5: Client decoder architecture.

TABLE 1: Experimental test environment.

\begin{tabular}{lc}
\hline Name & Parameter \\
\hline System & Windows 10 \\
CPU & $2.16 \mathrm{GHz} \backslash 800 \mathrm{MHz} \backslash 2 \mathrm{MB}$ \\
Development tool & Sublime \\
Deep learning tools & Theano \\
\hline
\end{tabular}

transmission process is different; so, the time interval between data packets also changes. Because the streaming audio and other data are transmitted synchronously, the video data stream needs to be multiplexed into one path in the transmission process. Saf multiplexes scene distribution and streaming video into one stream to ensure high video integration. The multiplexing structure is shown in Figure 4.

As can be seen from Figure 4, English teaching video data files are independent of each other [35]; so, it is necessary to find out the relationship between files for management, so as to reduce the workload of storing data and obtain the video's own information. Designing the video packaging and reuse structure can better improve the multilevel input-oriented English teaching model.

3.2. Client Design. The main function of the client window is to receive the scene distribution and video packets in the server and display the scene distribution of SVG and stream audio in the display screen and player.

There are many components in the video. The corresponding stream ID is defined for each component in the English teaching model. The user can demultiplex the video to be viewed according to the corresponding ID number and transmit it to the display screen. The decoder architecture is shown in Figure 5.

According to Figure 5, the problem that streaming transmission must face is caching data. Because the Internet is transmitted in the form of data packets, the real-time video will be decomposed into many small data packets in the transmission process. The transmission path of each data packet is different; so, the time to reach the client is also different, resulting in the disorder of the order between data packets and the sharp decline of the quality of English teaching model. Therefore, in order to ensure that the order of data packets arriving at the client is not changed [36], the cache system is adopted to ensure that the video is not delayed due to network congestion and improve the quality of the English teaching model. In most cases, the cache memory is too small. All caches will discard the played video and cache the content into the newly vacated space through the ring linked list in the cache.

Rich media browser is to display scene files and play streaming video, in which scene files need to be downloaded and played, while streaming video only needs to reorganize video frame level after receiving video data and mark time stamp at the same time.

To sum up, the multilevel input-oriented English teaching model displays the SVG files of scene distribution through batik. After receiving the scene distribution files, the client parses the files in DOM, which can ensure that the SVG files are saved in the mode of DOM parsing tree during the saving process, and ensures that it is easier for the laser instruction to adjust the scene tree. Therefore, the design of the multilevel input-oriented English teaching model considering diversified training objectives is realized.

\section{Experimental Analysis}

4.1. Experimental Environment and Process. In order to verify the feasibility of the multilevel input English teaching model considering diversified training objectives, the following experiments are designed. The experimental environment is shown in Table 1.

The experiment takes the English books in a university library as the experimental object of the multilevel input English teaching model to test the application performance of the teaching model. The test process is shown in Figure 6 .

According to the experimental flow in Figure 6, set the simulation test parameters, as shown in Table 2.

4.2. Analysis of Experimental Results. In order to verify the overall effectiveness of the proposed method, it is necessary to test the I/O performance and peak signal-to-noise ratio of the multilevel input English teaching model, reference [6] model, and reference [7] model considering diversified 


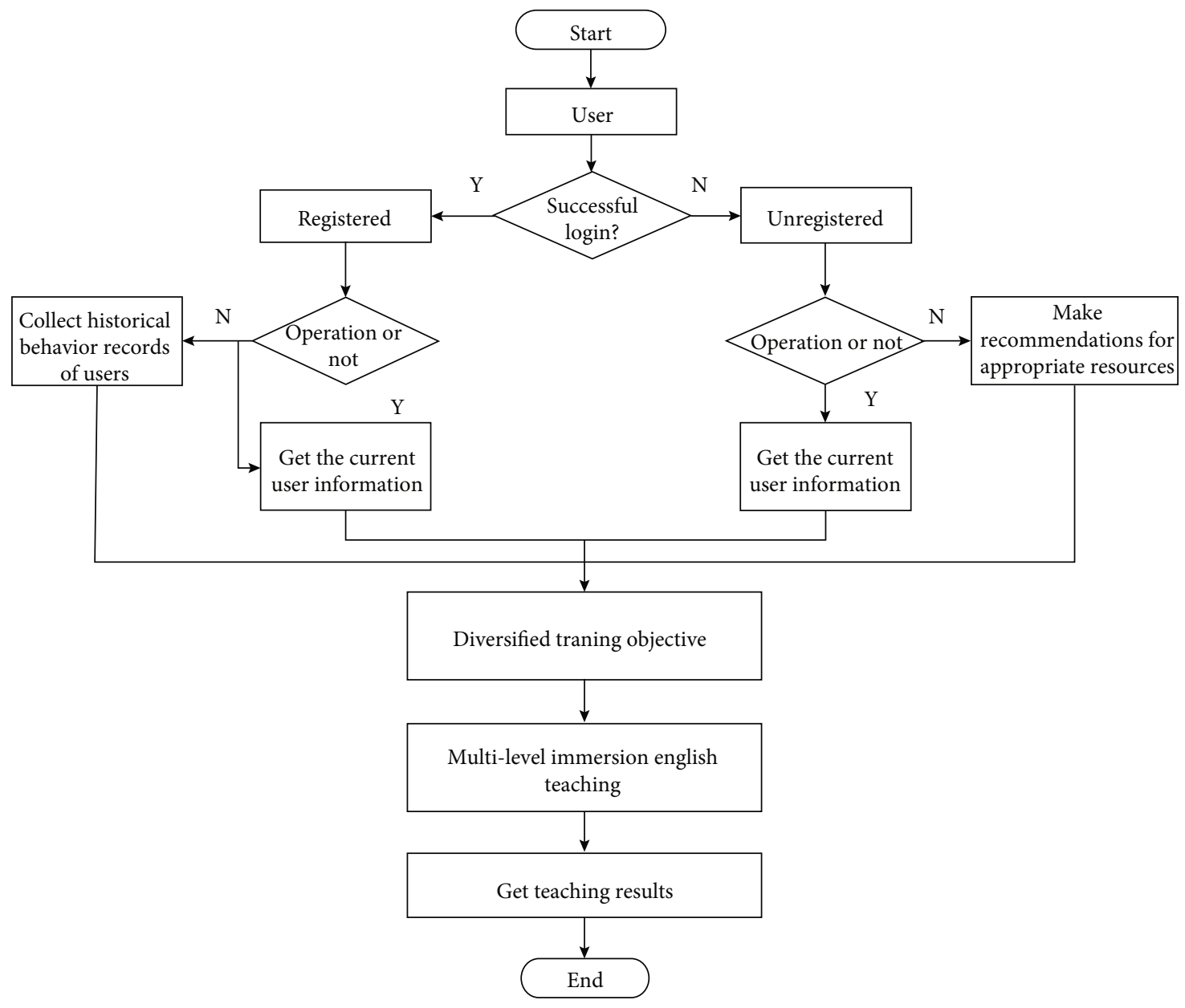

Figure 6: Experimental test flow.

TABLE 2: Experimental parameters of the system simulation test.

\begin{tabular}{|c|c|c|}
\hline Name & \multicolumn{2}{|c|}{ Parameter } \\
\hline Average processing time of network nodes in the multilevel input English teaching model & \multicolumn{2}{|c|}{$\leq 2 \mathrm{~h}$} \\
\hline Enter data batch size & \multicolumn{2}{|c|}{$128 \mathrm{Mb}$} \\
\hline Training rounds & \multicolumn{2}{|c|}{5 rounds } \\
\hline Number of different convolution kernels & \multicolumn{2}{|c|}{70} \\
\hline Convolution kernel type & \multicolumn{2}{|c|}{3 kinds } \\
\hline Hidden layer size & \multicolumn{2}{|c|}{$18 \times 2$} \\
\hline \multirow{6}{*}{ Full connection layer } & Layer 1 input & $128 \times L \times(18 \times 5)$ \\
\hline & Layer 1 output & 200 \\
\hline & Layer 2 input & 200 \\
\hline & Layer 2 output & $128 \times L \times(18 \times 5)$ \\
\hline & Layer 3 input & 200 \\
\hline & Layer 3 output & 200 \\
\hline
\end{tabular}

Note: $L$ stands for characteristic scale. 


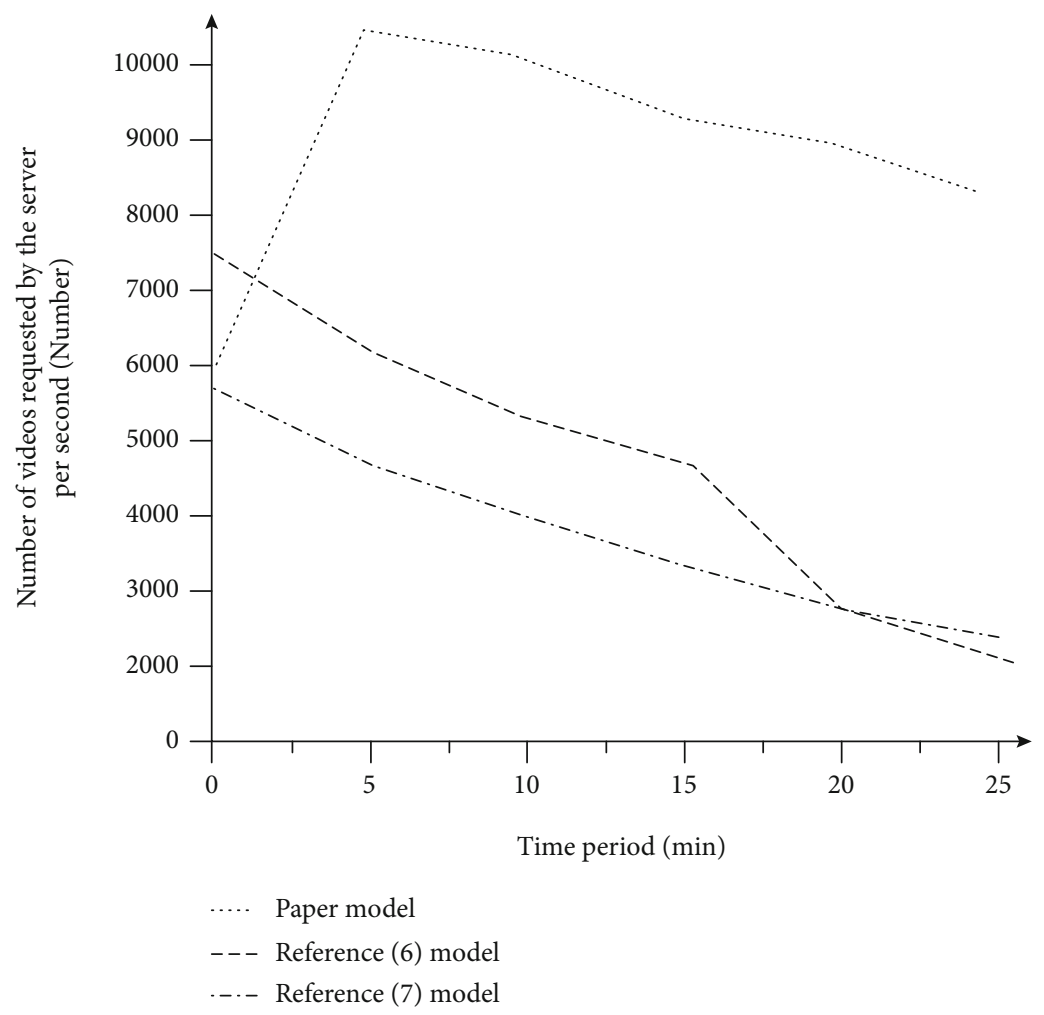

FigURE 7: I/O performance of different models.

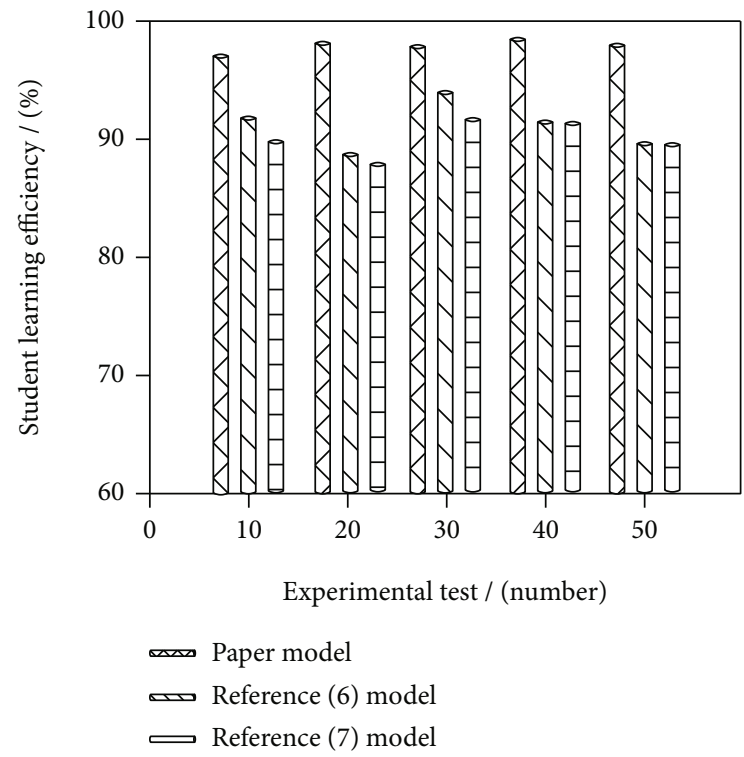

Figure 8: Comparison of learning efficiency of students with different models.

training objectives on the web platform. The I/O performance test results are shown in Figure 7:

By comparing the I/O performance of different methods, we can directly reflect the advantages and disadvantages of the system, operate the system for a long time, and give the same number of instructions to the three methods. According to Figure 7, it can be seen that the I/O performance will decline with the increase of time. The best I/O performance of reference [6] model and reference [7] model is only at the beginning of the system operation, which will directly lead to the poor degree of video streaming, The number of services available is too small, but the number of services in this model continues to increase in the first five minutes, and remains above 6000 even if it decreases later. This is because this model includes a portal and a streaming video server. Therefore, in the process of streaming video, it greatly improves the flexibility of English teaching video and can effectively cache English teaching model data. Thus, the $\mathrm{I} / \mathrm{O}$ performance of the model is improved.

Because the teaching assistance effects of different teaching models are inconsistent, the experiment focuses on comparing the changes of students' learning efficiency after model learning. The specific experimental comparison results are shown in Figure 8:

By analyzing the experimental data in Figure 8, it can be seen that the students' learning efficiency of the proposed model is significantly higher than that of the other two models, because this model sets autocorrelation feature mining, which effectively solves the problem of curriculum information loss and ensures the integrity of teaching scheme, so as to improve students' learning efficiency.

To sum up, the designed multilevel input-oriented English teaching model considering diversified training objectives will reduce the I/O performance with the increase of time. The number of services of this model continues to increase in the first five minutes, which greatly improves the flexibility of English teaching video in the process of 
streaming video, and can effectively cache English teaching model data, thus improving the I/O performance of the model. It can effectively solve the problem of curriculum information loss and ensure the integrity of teaching scheme, so as to improve students' learning efficiency.

\section{Conclusion and Prospect}

Aiming at a series of problems existing in the traditional model, a multilevel input-oriented English teaching model considering diversified training objectives is proposed. The experimental results show that the proposed model greatly improves the flexibility of English teaching video, effectively caches English teaching model data, and then improves the I/O performance of the model. At the same time, it can not only improve the learning efficiency of college students but also strengthen the teaching quality.

In the future, more in-depth research can be carried out on the following aspects:

(1) This paper is aimed at cultivating students' sense of responsibility and autonomous learning ability, creating a learning environment for social activities, building a new knowledge system, and cultivating students' critical reading ability

(2) The knowledge of intercultural communication is dynamic and will change with the continuous development of the environment and the times. Both teachers and students should have the awareness and creativity of development, learn to distinguish the true and false of cultural phenomena, and avoid the formation of "cultural stereotypes". Further research is needed in the future

\section{Data Availability}

The raw data supporting the conclusions of this article will be made available by the authors, without undue reservation.

\section{Conflicts of Interest}

The authors declared that they have no conflicts of interest regarding this work.

\section{Acknowledgments}

This work was supported by the fund project: the Phased Achievements of the Provincial Teaching Research Project of Higher Education in Hubei Province in 2020 (research on school-based construction and practice of online and offline hybrid "first-class courses" of College English. No. 2020699).

\section{References}

[1] T. Al-Habsi, S. Al-Busaidi, and A. Al-Issa, "Integrating technology in English language teaching through a community of practice in the Sultanate of Oman: implications for policy implementation," Educational Research for Policy and Practice, vol. 21, no. 1, pp. 1-10, 2021.

[2] M. S. Yadav and M. K. Yadav, "Role of the transformational generative grammar and other language learning theories in English language teaching," Electronic Research Journal of Social Sciences and Humanities, vol. 2, no. 1, pp. 142-153, 2020.

[3] H. A. Ozturk, "My quest for negotiating meaning. Reflections on my dilemmas about practices of English language teaching in public school context in Turkey: an autoethnography," Technium Social Sciences Journal, vol. 7, no. 1, pp. 36-48, 2020.

[4] V. N. Tarrayo, R. R. Potestades, and M. B. Ulla, "Exploring the gender perspective in English language teaching (ELT): voices from ELT practitioners in Philippine higher education institutions," Sexuality \& Culture, vol. 25, no. 5, pp. 1634-1652, 2021.

[5] L. Unsworth and K. A. Mills, "English language teaching of attitude and emotion in digital multimodal composition," Journal of Second Language Writing, vol. 47, no. 4, article 100712, 2020.

[6] A. E. Yastibas, "Evaluating an English language teaching program in terms of peace education," Shanlax International Journal of Education, vol. 8, no. 4, pp. 11-19, 2020.

[7] N. Badjadi, "Learner-centered English language teaching: premises, practices, and prospects," Journal of Education, vol. 8, no. 1, pp. 7-27, 2020.

[8] L. Tajik, K. Karimi, and A. Ramezani, "Realization of preemptive focus on form in the English-language teaching context," Open Linguistics, vol. 6, no. 1, pp. 094-108, 2020.

[9] G. Immanuel, G. Sankar, V. Saravanan, and M. Jose, "Significance of interpersonal skills and english language teaching," Materials Today: Proceedings, vol. 24, no. 2, pp. 74-79, 2021.

[10] B. Poole, "World Englishes in English language teaching global Englishes for language teaching," ELT Journal, vol. 74, no. 7, pp. 351-355, 2020.

[11] I. U. Khan, G. Rahman, and A. Hamid, "Poststructuralist perspectives on language and identity: implications for english language teaching research in pakistan," Sir Syed Journal of Education \& Social Research (SJESR), vol. 4, no. 1, pp. 257267, 2021.

[12] C. Kristjánsson, "English language teaching: locating faith in the context of local and global dynamics," International Journal of Christianity and English Language Teaching, vol. 6, no. 1, pp. 5-15, 2019.

[13] N. Toprakci and B. Özaydinli, "Textbooks in english language teaching in view of globalisation, localisation and glocalisation," International Journal of Teaching \& Education, vol. 8, no. 2, pp. 853-883, 2021.

[14] N. Oeamoum and C. Sriwichai, "Problems and needs in English language teaching from the viewpoints of pre-service English teachers in Thailand," Asian Journal of Education and Training, vol. 6, no. 4, pp. 592-601, 2020.

[15] A. S. Daif-Allah and F. H. Aljumah, "Developing the English language teaching skills of Saudi teachers of young learners," English Language Teaching, vol. 13, no. 3, pp. 20-30, 2020.

[16] L. Gashi, "Intercultural awareness through English language teaching: the case of Kosovo," Interchange, vol. 52, no. 3, pp. 357-375, 2021.

[17] H. H. Alsowat, "Evidence-based practices of English language teaching: a meta-analysis of meta-analyses," English Language Teaching, vol. 13, no. 11, pp. 75-82, 2020. 
[18] C. D. Yildiz, "Ideal classroom setting for English language teaching through the views of English language teachers (a sample from Turkey)," English Language Teaching, vol. 13, no. 3, pp. 31-44, 2020.

[19] J. Rahmati, S. Izadpanah, and A. Shahnavaz, "A meta-analysis on educational Technology in English language teaching," Teaching Language Testing in Asia, vol. 11, no. 1, pp. 1-10, 2021.

[20] A. E. Yastibas, "An anthropocentric approach to evaluate English language teaching course books,"Journal of Education, vol. 8, no. 3, pp. 24-29, 2020.

[21] S. Yohanova, "Technologies in English language teaching and learning," Economic Science, Education and the Real Economy: Development and Interactions in the Digital Age-Volume IV, pp. 736-743, 2020.

[22] M. A. Shahid, S. Kamran, A. Razi, S. Sajid, and I. Hussain, "Journal of English Language Teaching and Applied Linguistics Phonological Process in Toddlers" Single-Word Production: An Explorative Study of Alveolar Sounds in English," Phonology, vol. 14, no. 3, pp. 1-10, 2021.

[23] L. F. Ding and X. X. Wang, "A comparative study on English language teaching activities in kindergartens organized by Chinese teachers and foreign teachers," Journal of Shaanxi Xueqian Normal University, vol. 35, no. 2, pp. 65-69, 2019.

[24] M. Marwa, B. Y. Cahyono, M. A. Latief, and J. A. Prayogo, "Intercultural topics in the indonesian english language teaching classroom: contextualizing local and neutral cultures to target and global cultures," Journal of Intercultural Communication, vol. 21, no. 1, pp. 34-45, 2021.

[25] T. Wenping, "An integrating approach in English language teaching - - the combination of traditional and communicative approaches," Overseas English, vol. 2, 2019.

[26] Y. Sun, "On the influence of English language teaching model on students," The Guide of Science \& Education, vol. 1, pp. 246-248, 2019.

[27] Q. Wang, X. Qian, and M. Zhou, “Text analysis in English language teaching-importance and methods," Foreign Language Education in China, vol. 2, no. 2, 2019.

[28] J. Si, "English as a lingua franca: a new approach for English language teaching in China?," Chinese Journal of Applied Linguistics, vol. 42, no. 1, pp. 113-135, 2019.

[29] J. Huang, K. Y. N. Lock, and F. Teng, "Autonomy in English language teaching: a case study of novice secondary school teachers in Hong Kong," Chinese Journal of Applied Linguistics, vol. 42, no. 1, pp. 3-20, 2019.

[30] A. Orhan, "The experiences of students in English language teaching on learning "German as a foreign Language"," Journal of Education and Learning, vol. 8, no. 4, pp. 112-123, 2019.

[31] L. Luhan, "The problems of main English language teaching methods for Chinese college students," Overseas English, vol. 5, pp. 273-274, 2019.

[32] J. Fan, “Chinese ESL Learners' Perceptions of English language teaching and learning in Australia," Language Teaching, vol. 12, no. 7, 2019.

[33] M. A. K. Alenizi, "Understanding of reading among teachers and learners: a descriptive study of pre-university English language teaching/learning in Saudi Arabia," Arab World English Journal, vol. 10, no. 2, pp. 10-20, 2019.

[34] E. F. Boucher-Yip, "English language teaching in South America. Policy, preparation and practices," Current Issues in Language Planning, vol. 20, no. 2, pp. 199-202, 2019.
[35] A. Khoreva, R. Benenson, E. Ilg, T. Brox, and B. Schiele, "Lucid data dreaming for video object segmentation," International Journal of Computer Vision, vol. 127, no. 9, pp. 1175-1197, 2019.

[36] K. B. Fang, Z. W. Qin, C. Y. Yang, and C. K. Wang, "Password I ock SMS dynamic password public verification simulation in mobile terminal," Computer Simulation, vol. 36, no. 4, pp. 115-119, 2019. 